\title{
Reversing the reinforcement contingencies* of eating and keypecking behaviors
}

\author{
LEONARD P. SAWISCH and M. RAY DENNY \\ Michigan State Ciniversity, East Lansing, Michigan 48823
}

\begin{abstract}
Four of five pigeons were conditioned to peck a key at a high, stable rate on a VI schedule and then given concurrent access to free food. It was found, in replication of Neuringer's results, that the pigeons pecked a key for grain in the presence of free grain. When availability of the response key (high-probability response) was made contingent on eating free grain (a lower probability response), there was a progressive increase in free-food eating. confirming Premack's reinforcement principle. For two additional birds. when availability of the key was made contingent on not eating the free food (a type of DRO schedule), the frequency of free-food eating declined. Thus. availability of the key. depending on the contingency, reinforced both the eating and noneating of free food.
\end{abstract}

Premack (1959) has described reinforcement as a high-probability behavior that, when contingent on a low-probability response, increases the probability of the low-probability behavior. Neuringer (1970) demonstrated that pigeons conditioned for many sessions on a VI 1-min schedule would later continue to peck for food, even though free food of identical type was available. In Premack's terms, Neuringer made keypecking a higher probability behavior than free-food eating. This suggests the intriguing possibility of increasing the probability of free-food eating by reinforcing it with the opportunity to peck the key or, in other words, to condition a relatively hungry pigeon to eat by reinforcing it with the opportunity to peck the key, the exact opposite of the traditional experimental paradigm (contingency reversal)!

To test the possibility of reinforcing free-food eating with the opportunity to peck the key, the present study was divided into four experiments: The first duplicated Neuringer's work for verification purposes and then at tempted contingency reversal. The second experiment duplicated the training portion of Neuringer's work and then began contingency reversal. The third involved an alternate means of establishing baseline, using VI 30-sec instead of VI 1-min reinforcement, and then began contingency reversal. The fourth experiment constituted a control for the occurrence of noncontingent tree-food eating whenever the key was removed during contingency reversal. This control consisted of reinforcing $S$ whenever it failed to eat free food for a specified period (DRO). The reinforcement consisted of making the key accessible on VI $30 \mathrm{sec}$.

\section{EXPERIMENT 1}

Phase 1

\section{Procedure}

Thi, essentially was a duplication of Neuringer's entire

"Requests for reprints bould be ent to 11. Rid Denny.

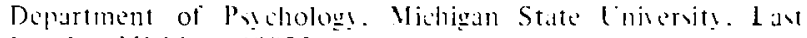
I aming. Yichigran 48823 procedure. Two previously experienced pigeons (191 and 503) were given 15 baseline sessions on a VI 1-min schedule, with 40 reinforcements per session. At the end of this period (baseline established), each S. still at $80 \%$; ad lib, was placed in the operant chamber with a large container of free food at one end of the box (the food was identical to seed in hopper). When $\mathrm{S}$ began to peck the free food ( $S$. thus, aware of free food). the keypeck equipment was turned on and left on for the remainder of the free-food session. When weight was again $80^{\%}$ ad lib. each $S w$ as given an additional baseline session, then a final free-food session. Typically, throughout this study 2 days separated successive sessions. but occasionally there were 3 . The two sessions were each approximately $60 \mathrm{~min}$ long.

\section{Results}

The results were much the same as Neuringer has reported. After an initial period of free-food eating (a mean of approximately $10 \mathrm{~min}$ ), both $\mathrm{Ss}$ began to peck the key for a total of 40 reinforcements from the standard food hopper, returning only occasionally to free food. Bird 503 returned five times in Session 1 and only twice in Session 2. Bird 191 returned five and six times in Sessions 1 and 2. respectively. The rate of pecking during these sessions was a mean of 27.5 pecks per reinforcement. substantially higher than the rate of returning to free food (a mean of .125 returns per access to hopper for both sessions for both birds).

\section{Phase 2}

Having established a condition in which keypecking was a high-probability and free-food eating a low-probability behavior, we attempted contingency reversal. During Phase 1, food reinforcement from hopper had been contingent on pecking the key. Now the opportunity to peck the key was contingent on eating free food.

\section{Proccdure}

The operant chamber contained a bin of free lood. and the keypeck equipment wats turmed on when $\mathrm{S}$ began to eat the fres food. When ke? peching began. the ke! remained avalable for fince it andard hopper reinforcements. This provided an additional 


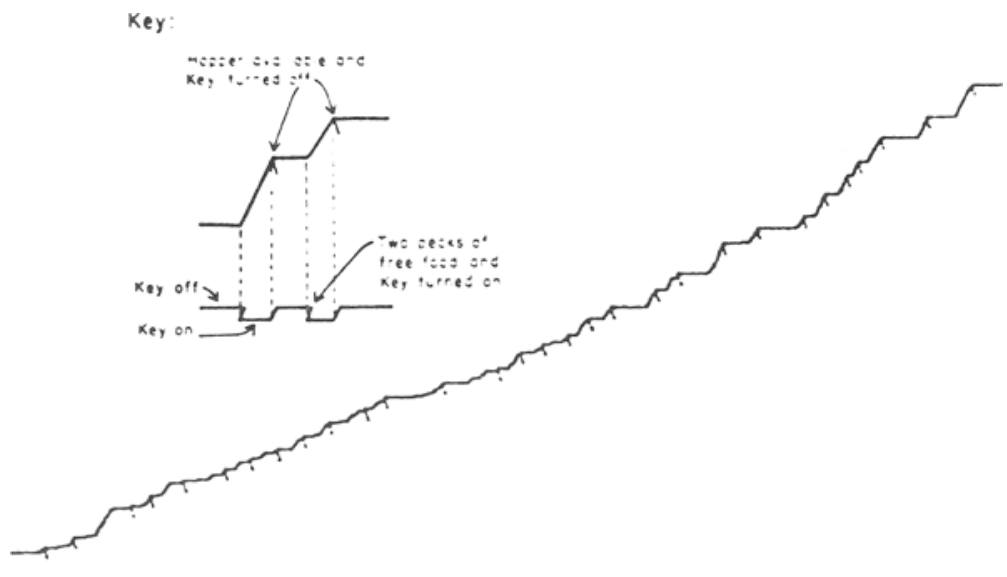

Fig. 1. Cumulative keypeck responding (upper curve) and contingent free-food eating (lower horizontal line) by Bird 410 throughout Session 3 of contingent reversal (Experiment II).

baseline (control) for free-food eating just prior to introducing the new contingency. After the fifth standard reinforcement and each access to the key-operated hopper thereafter, the equipment was shut off with the kerlight out and no longer operative. The key was made available again whenever $\mathrm{S}$ pecked the free food at least twice in quick succession. When the key was operative. S was on a VI 30 -sec schedule, with hopper available for $4 \mathrm{sec}$ of food reinforcement. The SD for approach to key after pecking free food was a solenoid click plus white light behind the key. To repeat, availability of the key was contingent on eating free food; these sessions were approximately $50 \mathrm{~min}$ long.

\section{Results}

During the free-food segment of these sessions, both birds returned to free food at approximately the same rate as during the free-food sessions of Phase 1 . Bird 503 on Session 1 of contingency reversal made nine contingent returns. a mean of .106 times/min. averaging 38 pecks after each return. Session 2 yielded six contingent returns to free food. $.165 / \mathrm{min}$ (time base varied as a function of time spent in free-food eating), with a mean of 20 pecks after each return. Session 3 yielded 16 contingent returns, .389 times $/ \mathrm{min}$, with a mean of 51 pecks after each return, clearly suggesting the operation of Premack's principle of reinforcement. Bird 191 on the first contingency reversal session made six contingent returns to free food, a mean of .245 times $/ \mathrm{min}$. and averaged 27 pecks after each return. On Session 2. Bird 191 made five contingent returns, .138 times/min, averaging 17 pecks after each return. A third session for Bird 191 was precluded because $S$ was destroyed prematurely by the laboratory caretaker. Thus. the evidence for learning a contingency reversal in Bird 191 is indeterminate or minimal.

\section{EXPERIMENT II}

In this experiment the baseline portion of Experiment I was duplicated. but the free-food sessions prior to contingency reversal were eliminated. The purpose here was to investigate the possibility of establishing a higher rate of contingency reversal than was found in Experiment I, i.e., by maximizing the strength of keypecking.

\section{Procedure}

One previously experienced pigeon (410) was given 14 sessions on a VI 1-min schedule. with 40 reinforcements per session. and then given the identical procedure outlined in Phase 2 of Experiment I. minus the free-food control segment.

\section{Results}

Session 1 of contingency reversal yielded seven contingent returns to free food, a mean of .500 times/min, with an average of 12 pecks after each return. On Session 2. S made 42 contingent returns. a mean of .810 times/min, averaging 14 keypecks after each return. Session 3 yielded 31 contingent returns, .696/min. with an average of 13 pecks after each return. The cumulative curve in Fig. 1 shows the overall steady rate of these responses and the relatively quick return to the key each time it was made available.

\section{EXPERIMENT III}

An alternative procedure for establishing a high rate of pecking and a low rate of free-food eating was instituted.

\section{Procedure}

Iwo experimentally naive pigeons (82 and 1001 ) were keypeck trained for 15 sessions on a VI $30-\mathrm{sec}$ schedule. with 40 reinforcements per session. Contingency reversal sessions were then run following the procedure outlined in Phase 2 of Ixperiment I. minus the free-food control segment.

\section{Results}

Bird 82. which never established a steady rate of 
response during the baseline sessions, failed to peck the key during two contingency reversal sessions, serving in a sense as a control for the relevance of first establishing a high-probability keypeck response.

On Session 1 of contingency reversal, Bird 1001 made eight contingent returns, a mean of $.512 / \mathrm{min}$, averaging 10 pecks after each return. On Session 2. S made 18 contingent returns, $.625 / \mathrm{min}$, and averaged 17 pecks after each return. During the last session, $\mathrm{S}$ made eight contingent returns to free food, .666 times/min, with an average of nine pecks after each return. The two curves in Fig. 2 nicely illustrate the acquisition of the reversal contingency by Bird 1001 as Session 2 progressed, that is, an increase in contingent returns to free food in the lower curve and an increase in keypecking in the upper cumulative curve.

\section{EXPERIMENT IV}

This experiment was done as a control for the possibility that the increase in the rate of returns to free food was a direct result of the key being off rather than a result of contingency reversal. One convenient control is to condition pigeons on exactly the opposite contingency, with $\mathrm{S}$ being reinforced (given access to the key) for not eating free food, a DRO schedule. Such a control has recently been evaluated as being especially rigorous (Gootz. Helmberg. \& LeBlanc, 1972).

\section{Procedure}

Two naive pigeons ( 9 and 10) were given 15 sessions on a VI 1 -min schedule, with 40 reinforcements per session. After this. each bird was given two sessions on a DRO $60-\mathrm{sec}$ schedule (refraining from eating free food for at least $60 \mathrm{sec}$ ). The procedure was the same as in Phase 2 of Experiment I, except that the key was made available only' when $S$ did not eat free food for $60 \mathrm{sec}$. After the DRO 60-sec sessions, each $\mathrm{S}$ was given five additional baseline keypecking sessions under VI 1-min and then two sessions on a DRO $30-\mathrm{sec}$ schedule (key available after $30 \mathrm{sec}$ of no free-food cating).
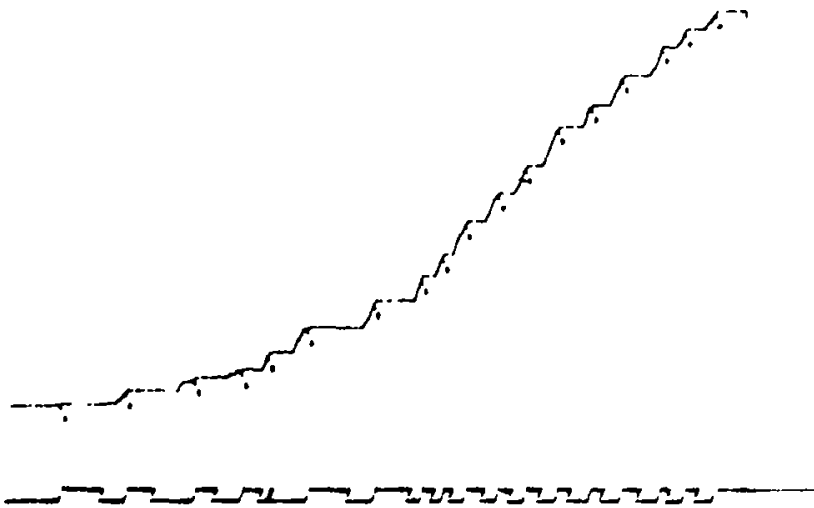

Fig. 2. Cumulative keypecking (upper curve) and free-food eating (lower line) by Bird 1001 throughout Session 2 of contingent reversal (E.speriment III). The key in Fig. 1 also applies to this figure.
Table 1

Response Summaries for the DRO 60- and DRO 30-Sec Schedules

\begin{tabular}{cccc} 
& Ratio of & Percent & \\
Contingent & Returns & \\
Noneating & to Free & \\
& Time to & Food Before & Pecks \\
Ses- & Total Time & Waiting & Per \\
sion & Key is Off & the Interval & Minute \\
\hline
\end{tabular}

\begin{tabular}{lllll}
\hline Bird 9 & & & & \\
DRO 60 & 1 & .220 & 57 & 112 \\
& 2 & .302 & 73 & 138 \\
DRO 30 & 1 & .581 & 50 & 138 \\
Bird $10^{*}$ & 2 & .606 & 19 & 99 \\
DRO 60 & & & & \\
DRO 30 & 2 & .508 & 33 & 63 \\
\hline
\end{tabular}

* Bird 10 never ceased eating free food during Session 1 of each $D R O$ schedule, so there are no data to report for these sessions.

\section{Results}

The results are summarized in Table 1 . Column 1 of the table refers to the general efficiency of inhibiting the eating of free food so that the key becomes available: the higher the ratio, the less time the bird spent eating free food while the key was off. Column 2 refers to the percentage of times $S$ returned at least once to the free food, each time the key was removed. without first waiting the DRO interval. Column 3, pecks per minute. shows a steady but moderate rate of responding to the key when it was available, rates that were in excess of the rates in the other three experiments (since $S$ had to wait extended periods under the DRO schedule without a key to peck and without eating free food, it seems plausible to suggest that the higher pecking rate under DRO may be a systematic effect due to the frustration from extended waiting that immediately preceded key availability).

The data in Table 1 indicate that Bird 9 showed a progressive increase in contingent noneating behavior and an eventual low level of $19 \%$ free-food eating each time the key was turned off. Bird 10 on the initial sessions of both DRO 60 and DRO 30 ate free food continually and failed to peck the key. On each of the second sessions, however. this $S$ had a high rate of contingent noneating behavior and a low percentage of returns to free food when the key was removed. Acquisition of this DRO behavior in Bird 10 for the 60 -sec contingency is nicely portrayed in the lower curve of Fig. 3. The duration of the raised part of the lower line begins long and decreases to a minimum (the 60-sec DRO wait), so that Bird 10 ends the sessions with a high rate of contingent noneating behavior.

\section{Group Results}

To supplement the descriptive presentation of data in Experiments I. II. and III. the statistical significanci of the increase of contingemt returns to free fond was 


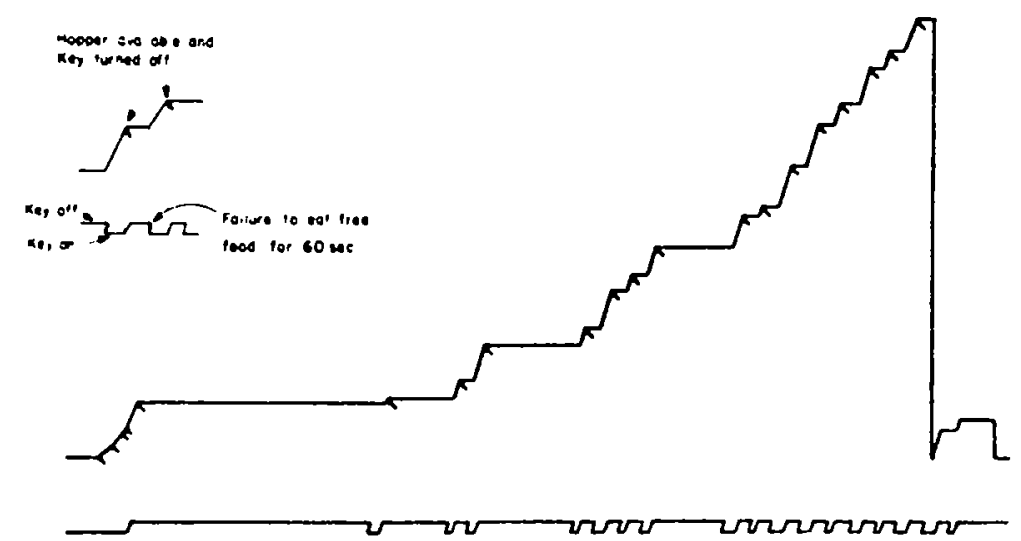

Fig. 3. Cumulative keypecking (upper curve) and failure to eat free food for $60 \mathrm{sec}$ (lower line) by Bird 10 in Session 2 of DRO $60 \mathrm{sec}$. tested. Bird 82 was eliminated for failure to keypeck (no reinforcement present). For all other birds except 191. the rate of contingent returns in the first contingency reversal session was compared with the mean rate in the last two sessions. For Bird 191 (Experiment I), because data were available for only two contingency reversal sessions. the mean rate of contingent returns for these two sessions was compared to the mean rate of noncontingent returns during the free-food eating sessions of Phase 1 and the brief initial control segments of Phase 2. The prepost mean returns to the free-food bin per minute were .306 and .464 , respectively. For this mean difference, $\mathrm{t}$ was $4.31(\mathrm{df}=3, \mathrm{p}<.05)$.

\section{DISCUSSION}

One of the important aspects of the present results is that they demonstrate learning of a reversed contingency via Premack's principle of reinforcement without the necessity of satiating $\mathbf{S}$ for the traditional reinforcement (in this case, food). That is. in a prior demonstration of a reversal of the traditional contingency (Premack. 1962). the experimental Ss were satiated for the incentive of water prior to training them to lick water in order to have access to an activity wheel. The present demonstration is particularly convincing because availability of the key. depending on the contingency, could reinforce either the occurrence or nonoccurrence of free-food eating.

The present results are also compatible with the contiguity notions of elicitation theory. in which operant and instrumental learning are redefined in terms of classical conditioning principles (Denny, 1971). According to this position, the basic UR. broadly defined. is approaching the incentive, and the CR (learned operant) is a member of the large response class of approach that can come forward in the behavior sequence. Thus, the learned approach value of the key (a CS serving as a functional US) presumably mediates the learning of any instrumental "approach" response that consistently' produces the US (in this case. the key). just as hopper noise and light presumably mediate keypecking or key approach and perception of food in hopper mediates magazine training (a backchaining analysis).

\section{REFERENCES}

Denny. M. R. A theory of experimental extinction and its relation to a general theory. In H. H. Kendler and J. T. Spance (Eds.). Essa!'s in neobehaviorism: A memorial rolume to Kenneth W'. Spence. New York: Appleton-Century-Crofts. 1971

Gootz. E. M.. Helmberg, M. C., \& LeBlanc. J. M. The comparison of two different control procedures during the modification of a preschooler's compliance behavior. Paper presented at the annual meeting of the American Psychological Association. 1972.

Neuringer, A. J. Many responses per food reward with free food present. Science. 1970. 169. 503-504.

Premack. D. Toward empirical behavior laws: I. Positive reinforcement. Psychological Review. 1959. 66. 219-233.

Premack. D. Reversibility of the reinforcement relation. Science. 1962. 136. 255-257.

(Received for publication February 14. 1973: revision received April 16. 1973.) 